Original Research Article

\title{
Comparative efficacy and safety of DPP-4 inhibitors and $\alpha$-glucosidase inhibitors as add on therapy in type 2 diabetes
}

\author{
Rajit Sahai $^{1 *}$, Taruna Sharma ${ }^{1}$, Dilip C. Dhasmana1, Nidhi Kaeley ${ }^{2}$
}

\begin{abstract}
${ }^{1}$ Department of Pharmacology, ${ }^{2}$ Department of General Medicine, Himalayan Institute of Medical Sciences, Dehradun, Uttarakhand, India
\end{abstract}

Received: 20 January 2018 Accepted: 05 March 2018

*Correspondence to:

Dr. Rajit Sahai,

Email: sahairajit@gmail.com

Copyright: (C) the author(s), publisher and licensee Medip Academy. This is an openaccess article distributed under the terms of the Creative Commons Attribution NonCommercial License, which permits unrestricted noncommercial use, distribution, and reproduction in any medium, provided the original work is properly cited.

\begin{abstract}
Background: Diabetes mellitus (DM) is a spectrum of metabolic disorders as a consequence of different pathogenic mechanisms resulting in hyperglycemia. A genetic predisposition to develop $\beta$-cell dysfunction synergizes with insulin resistance to lead to type $2 \mathrm{DM}$. Adequate management of type $2 \mathrm{DM}$ requires institution of non pharmacological treatment followed by pharmacological treatment. Monotherapy is started initially followed by combination therapy (dual/triple). Sitagliptin, a DPP-4 inhibitor and voglibose, an $\alpha$-glucosidase inhibitor has been implicated as an add on therapy to metformin and glimepiride. So, we aimed to assess the efficacy and safety of the sitagliptin and voglibose as add on therapy to metformin and glimepitide in type $2 \mathrm{DM}$.

Methods: This open label randomized control trial was conducted in the department of Pharmacology among patients attending medicine OPD of a tertiary care hospital. 80 patients were randomly divided into two groups of 40 patients each. group A:sitagliptin + metformin + glimepiride and group B:voglibose + metformin + glimepiride. Patients were followed every week for a period of 12 weeks. Data was analysed using paired t test, unpaired t test and chi square test.
\end{abstract}

Results: There was a significant decrease in HbA1c, FPG and PPG in both the groups. Intergroup comparison at 4, 8 and 12 weeks showed a better improvement in glycemic control in group A as compared to group B.

Conclusions: Sitagliptin showed a better glycemic control than that with voglibose in patients with uncontrolled type $2 \mathrm{DM}$ on metformin and glimepiride.

Keywords: Type 2 diabetes, Sitagliptin, Voglibose

\section{INTRODUCTION}

DM is a group of common metabolic disorders that are characterized by hyperglycemia. Contributory factors leading to hyperglycemia are reduced insulin secretion, decreased glucose utilization and increased glucose production. ${ }^{1}$ The worldwide prevalence of DM has risen drastically over the past two decades, from an estimated 30 million cases in 1985 to 382 million in 2013. Based on current trends, the International Diabetes Federation projects that 592 million individuals will have diabetes by the year 2035. Although the prevalence of both type 1 and type $2 \mathrm{DM}$ is increasing worldwide, the prevalence of type
$2 \mathrm{DM}$ is rising much more rapidly, presumably because of increasing obesity and reduced physical activity. ${ }^{2}$

Hyperglycemia is a key factor leading to complications of type 2 diabetes and therefore, reducing it is a critical aim. ${ }^{3}$ Optimal management of type 2 diabetes requires control of glycosylated haemoglobin (HbAlc), fasting plasma glucose (FPG) and postprandial glucose (PPG) (the glucose triad), ideally through a combination of lifestyle modification and appropriate drug therapy. ${ }^{4}$

Among the available oral anti diabetic agents, metformin is most commonly used, both as a monotherapy and in combination with other oral anti diabetic agents. ${ }^{5}$ Type 2 
diabetes is a progressive illness, with most patients experiencing a progressive deterioration in glycemic control so treatment with a single oral anti diabetic agent is often unsuccessful at achieving glycemic control in subjects with type 2 DM. $^{6}$ Therefore a dual combination therapy is needed. The most popular dual combination treatment for uncontrolled type $2 \mathrm{DM}$ is metformin and sulfonylureas. ${ }^{7}$

Among the sulfonylureas glimepiride is considered to have a greater potency and better safety profile and is the commonest to be prescribed with metformin. ${ }^{8}$ Nevertheless, dual combination therapy with metformin and a sulfonylurea may not achieve or maintain adequate glycemic control. ${ }^{6}$ This necessitates the addition of a third oral anti diabetic agent which is increasingly being used in clinical practice. ${ }^{9}$

Sitagliptin, a dipeptidyl peptidase-4 (DPP-4) inhibitor has been shown to improve glycemic control and to be welltolerated in large multinational, placebo-controlled and active-controlled trials both as monotherapy and when given in combination with other oral anti diabetic agents. ${ }^{10}$ DPP-4 inhibition leads to an increase in the concentration of the incretins i.e. glucagon like peptide-1 and glucose dependent insulinotropic polypeptide. These incretins help in insulin secretion from the $\beta$-cell of pancreas and ultimately result in achieving glycemic control. ${ }^{11}$

Voglibose, a $\alpha$-glucosidase inhibitor has shown efficacy with a relatively favourable safety profile and is recommended to be given in combination with other oral anti diabetic agents. $\alpha$-glucosidase inhibition results in a decrease in the carbohydrate absorption (converted to glucose) from the intestine and thereby leading to a decrease in the blood sugar levels. ${ }^{12}$

Given the increasing complexities in managing type $2 \mathrm{DM}$, interest in the development, use and potential benefits of combination therapies has grown steadily. ${ }^{13}$ Although both of these drugs are commonly used nowadays but due to scarcity of data on head to head comparison of sitagliptin and voglibose as an add on therapy to metformin and glimepiride; we planned this study to compare the efficacy and safety of these drugs and to test the hypothesis that sitagliptin is better than voglibose in achieving glycemic control.

\section{METHODS}

The study was conducted in the Department of Pharmacology in collaboration with Department of General Medicine of the Himalayan Institute of Medical Sciences, Swami Ram Nagar, Dehradun over a period of twelve months (January 2016 to December 2016). The study protocol was approved by the Institutional Ethics Committee. Patients presenting to Medicine OPD with type 2 diabetes were recruited in the study after taking written informed consent.

\section{Study design}

It was an open label randomized control trial. On the basis of OPD records of previous years a total of 80 patients were included in the study.

\section{Inclusion criteria}

- $\quad$ Patients with uncomplicated type 2 Diabetes Mellitus

- Uncontrolled Type 2 DM patients taking maximum tolerated dose of Metformin (2gm/day) and Glimepiride ( $3 \mathrm{mg} /$ day)

- Patients of either sex between 18-60 years of age

- $\mathrm{HbA} 1 \mathrm{c} \geq 8.5 \%$.

\section{Exclusion criteria}

- Patients with type 1 Diabetes Mellitus

- Patients with any acute or long term clinically detectable complication

- $\mathrm{HbA} 1 \mathrm{c}<8.5 \%$

- Pregnant/Lactating women

- $\quad$ eGFR $<60 \mathrm{ml} / \mathrm{min} / 1.73 \mathrm{~m}^{2}$

- Any history of cardiovascular disease including congestive heart failure

- Any known hypersensitivity to these drugs

- Any co-morbid conditions.

Patients were randomly divided into two groups via simple random technique (40 each). Drugs were prescribed, and the doses titrated as per the physician's discretion. Group A $(n=40)$ patients received sitagliptin $(50-100 \mathrm{mg} /$ day $)$ with maximum tolerated dose of metformin and glimepiride. Group B $(n=40)$ patients received voglibose (0.2-0.9mg/day) with maximum tolerated dose of metformin and glimepiride.

Demographic details and history were recorded at the time of recruitment. A detailed physical examination was also done. Body mass index (BMI) and waist-hip ratio (WHR) were determined for all patients and recorded with above mentioned details in the same case-recording form. FPG, PPG and HbA1c were tested on the day of recruitment along with other baseline parameters. In addition, patients were also asked to follow individual dietary chart as advised by the physician and to maintain a diary.

Follow up: Patients were followed up every 4 weeks for a period of 12 weeks. During the follow up visit, patients were questioned about the adverse drug events and drug compliance. Body weight was measured, recorded and the patients were tested for FPG and PPG. HbAlc was tested at 12 weeks. WHR was also determined again at 12 weeks.

The primary end point was to achieve targeted HbA1c: $<7 \%$ or reduction upto $1.5 \%$ over 12 weeks and the secondary end point was to achieve targeted FPG: $80-$ 130mg/dl and PPG: <180mg/dl. 


\section{Data management and statistical analysis}

The treatment groups were compared and results were analyzed using available statistical software Microsoft excel 2007 and SPSS version 20.0. The demographic profile of the study population like age, duration of disease, BMI, serum creatinine and eGFR were expressed as mean and standard deviation. The family history, gender distribution, education status and addiction history were expressed as proportion. The pre and post therapy comparison of $\mathrm{HbA1c}$ and BMI in the same group was done by paired-t- test. Repeated measures like FPG and PPG at every month was tested using repeated measures ANOVA. Inter group comparison for HbA1c, FPG, PPG and BMI were done using unpaired- t-test. Secondary end point analysis of FPG was done using chi square test. Descriptive analysis was represented by graphical representation wherever required using Microsoft Excel 2007. Adverse drug events were analysed using descriptive statistics and intergroup analysis for the same was done using chi square test. A p value of $<0.05$ was considered significant.

\section{RESULTS}

Table 1: Demographic profile of patients included in study groups $\mathrm{A}$ and $\mathrm{B}$.

\begin{tabular}{|c|c|c|}
\hline Parameters & Group $A, n=40$ & Group B, n=40 \\
\hline Age (years) & $48.50 \pm 9.373^{*}$ & $46.27 \pm 9.578^{*}$ \\
\hline $\begin{array}{l}\text { Sex distribution } \\
\mathrm{M} / \mathrm{F}\end{array}$ & $18 / 22$ & $24 / 16$ \\
\hline $\begin{array}{l}\text { Positive family } \\
\text { history }\end{array}$ & 33 & 33 \\
\hline $\begin{array}{l}\text { Duration of } \\
\text { diabetes (years) }\end{array}$ & $8.00 \pm 3.588 *$ & $6.83 \pm 3.795^{*}$ \\
\hline \multicolumn{3}{|l|}{ Education Status } \\
\hline Metric & 8 & 14 \\
\hline Intermediate & 13 & 17 \\
\hline Graduate & 19 & 9 \\
\hline Rural/Urban & $8 / 32$ & $6 / 34$ \\
\hline $\begin{array}{l}\text { Diet: Veg/ Non } \\
\text { veg }\end{array}$ & $25 / 15$ & $27 / 13$ \\
\hline \multicolumn{3}{|l|}{ Addiction } \\
\hline Smoker & 6 & 13 \\
\hline Alcoholic & 13 & 27 \\
\hline BMI $\left(\mathrm{kg} / \mathrm{m}^{2}\right)$ & $26.999 \pm 2.641^{*}$ & $26.075 \pm 2.979^{*}$ \\
\hline $\begin{array}{l}\text { Waist-hip ratio, } \\
\text { Males }\end{array}$ & $1.033 \pm 0.108 *$ & $0.975 \pm 0.115 *$ \\
\hline $\begin{array}{l}\text { Waist-hip ratio, } \\
\text { Females }\end{array}$ & $1.004 \pm 0.089 *$ & $1.037 \pm 0.050 *$ \\
\hline $\begin{array}{l}\text { Serum creatinine } \\
(\mathrm{mg} / \mathrm{dl})\end{array}$ & $0.703 \pm 0.147 *$ & $0.752 \pm 0.144 *$ \\
\hline $\begin{array}{l}\text { eGFR } \\
\left(\mathrm{ml} / \mathrm{min} / 1.73 \mathrm{~m}^{2}\right)\end{array}$ & $116.609 \pm 31.756^{*}$ & $111.638 \pm 32.534 *$ \\
\hline HbA1c (\%) & $9.895 \pm 0.148^{*}$ & $9.855 \pm 0.141 *$ \\
\hline FPG (mg/dl) & $176.15 \pm 11.641^{* \#}$ & $181.95 \pm 11.873^{*}$ \\
\hline PPG (mg/dl) & $264.73 \pm 15.768 * \#$ & $272.25 \pm 15.060 *$ \\
\hline
\end{tabular}

Values expressed as Mean \pm SD, \#p value $<0.05$ versus Group B baseline values
All the baseline characteristics were comparable between the two groups except the baseline FPG and PPG values. Baseline HbA1c, FPG and PPG in both group A and group $\mathrm{B}$ were higher than the normal value (Table 1). The daily dose of metformin and glimepiride used in both the groups were $2 \mathrm{~g}$ and $3 \mathrm{mg}$ respectively. The mean daily dose of sitagliptin in Group A was 77.5 \pm 25.191 and that of voglibose in Group B was $0.645 \pm 0.108$.

HbA1c reduction was observed in both the groups. In group A the mean reduction at 12 weeks was $0.48 \%$ which was statistically significant $(\mathrm{p}<0.05)$, whereas in group B the reduction in $\mathrm{HbAlc}$ was $0.23 \%$ which was also statistically significant $(\mathrm{p}<0.05)$. None of the patients in both the groups achieved HbA1c goal of $<7 \%$ or a reduction of $1.5 \%$. In terms of weight reduction there was significant reduction in both the treatment groups $\mathrm{A}$ $(\mathrm{p}<0.05)$ and $\mathrm{B}(\mathrm{p}<0.05)$ which was reflected in the BMI (Table 2).

Table 2: Pre and post therapy comparisons of HbA1c and BMI in both the study groups.

\begin{tabular}{|lll|l|}
\hline Parameter & Group & $\begin{array}{l}\text { Baseline } \\
\text { mean } \pm \text { SD }\end{array}$ & $\begin{array}{l}\text { 12 weeks } \\
\text { mean } \pm \text { SD }\end{array}$ \\
\hline $\begin{array}{l}\text { HbA1c } \\
(\%)\end{array}$ & A & $9.895 \pm 0.148$ & $9.407 \pm 0.140 *$ \\
\hline BMI & B & $9.855 \pm 0.141$ & $9.620 \pm 0.150 *$ \\
\hline$\left(\mathrm{kg} / \mathrm{m}^{2}\right)$ & B & $26.999 \pm 2.64$ & $26.798 \pm 2.592^{*}$ \\
\hline
\end{tabular}

Paired t test, $* \mathrm{p}<0.05$ versus corresponding baseline values

The reduction in mean FPG levels measured in the outpatient clinic (mean of all measurements during 12week period) was significant in both the study groups $(p<0.05)$. The FPG reduced 4 weeks after initiation of therapy and continued to decrease further. The mean change reduction in FPG at 4,8 and 12 weeks from baseline was statistically significant both in group A $(\mathrm{p}<0.05)$ and in group B $(\mathrm{p}<0.05)$ (Table 3$)$. PPG was also reduced in both the groups 4 weeks after initiation of therapy. The mean change reduction in PPG at 4,8 and 12 weeks was statistically significant both in group A $(\mathrm{p}<0.05)$ and in group B $(\mathrm{p}<0.05)$ (Table 3$)$.

The inter group comparison for mean change in $\mathrm{HbA} 1 \mathrm{c}$ between group A and group B showed a significant difference between the two groups. The mean change was higher in group A $(\mathrm{p}<0.05)$ than in group $\mathrm{B}$. The mean change for BMI between the two groups was however non significant $(p=0.153)$ which was the direct result of minimal weight reduction in both the groups. In addition there was no significant change observed between the two groups in terms of change in waist-hip ratio at the end of 12 weeks (Table 4 ).

On comparison of mean change reduction of FPG and PPG at 4 weeks the mean change was significant for both FPG and PPG. The mean change at 4 weeks for FPG and PPG was higher in group A $(p<0.05)$ than in group B (Table 5). The mean change between group A and group B at 8 weeks 
was significant for both FPG and PPG. The change was higher in group A $(\mathrm{p}<0.05)$ for both FPG and PPG (Table 5). At 12 weeks the change in FPG between group A and group B was statistically significant as was with PPG. The mean change was found to be higher at 12 weeks in group A $(\mathrm{p}<0.05)$ than in group B (Table 5).

Table 3: Intra group analysis of FPG and PPG in both the study groups.

\begin{tabular}{|llllll|}
\hline Parameter & Group & $\begin{array}{l}\text { Baseline } \\
\text { Mean } \pm \text { SD }\end{array}$ & $\begin{array}{l}\text { 4 weeks } \\
\text { Mean } \pm \text { SD }\end{array}$ & $\begin{array}{l}\text { 8 weeks } \\
\text { Mean } \pm \text { SD }\end{array}$ & $\begin{array}{l}\text { 12 weeks } \\
\text { Mean } \pm \text { SD }\end{array}$ \\
\hline $\begin{array}{l}\text { FPG } \\
(\mathrm{mg} / \mathrm{dl})\end{array}$ & $\mathrm{A}$ & $176.15 \pm 11.641$ & $164.20 \pm 11.246^{*}$ & $148.93 \pm 11.025^{*}$ & $127.50 \pm 10.551^{*}$ \\
\hline $\begin{array}{l}\text { PPG } \\
(\mathrm{mg} / \mathrm{dl})\end{array}$ & $\mathrm{A}$ & $181.95 \pm 11.873$ & $175.30 \pm 11.316^{*}$ & $164.88 \pm 11.303^{*}$ & $151.45 \pm 10.471^{*}$ \\
\hline
\end{tabular}

Repeated measures ANOVA, * $\mathrm{p}<0.05$ versus corresponding baseline values

Table 4: Comparison of mean change of HbA1c and BMI from baseline up to 12 weeks between the study groups.

\begin{tabular}{|lll|}
\hline Parameter & Group & Mean change Mean \pm SD \\
\hline \multirow{2}{*}{ HbA1c $(\%)$} & A & $0.488 \pm 0.056^{*}$ \\
\cline { 2 - 3 } & B & $0.235 \pm 0.073$ \\
\hline \multirow{2}{*}{ BMI $\left(\mathrm{kg} / \mathrm{m}^{2}\right)$} & $\mathrm{A}$ & $0.200 \pm 0.184$ \\
\hline
\end{tabular}

Unpaired t test, *p<0.05 versus Group B values at 12 weeks

Table 5: Comparison of mean change of FPG and PPG from baseline up to 4, 8 and 12 weeks between the study groups.

\begin{tabular}{|lll|ll|}
\hline Parameter & Groups & $\begin{array}{l}\text { Mean change from } \\
\text { baseline to 4 weeks } \\
(\text { Mean } \pm \text { S.D. })\end{array}$ & $\begin{array}{l}\text { Mean change from } \\
\text { baseline to 8 weeks } \\
\text { Mean } \pm \text { S.D. }\end{array}$ & $\begin{array}{l}\text { Mean change from } \\
\text { baseline to 12 weeks } \\
\text { Mean } \pm \text { S.D. }\end{array}$ \\
\hline $\begin{array}{l}\text { FPG } \\
(\mathrm{mg} / \mathrm{dl})\end{array}$ & $\mathrm{A}$ & $11.95 \pm 1.108^{*}$ & $27.23 \pm 1.493^{*}$ & $48.65 \pm 2.045^{*}$ \\
\hline $\begin{array}{l}\text { PPG } \\
(\mathrm{mg} / \mathrm{dl})\end{array}$ & $\mathrm{B}$ & $6.65 \pm 1.578$ & $17.08 \pm 2.141$ & $30.50 \pm 4.679$ \\
\hline
\end{tabular}

Unpaired t test, *p<0.05 versus Group B mean change values at 4,8 and 12 weeks respectively

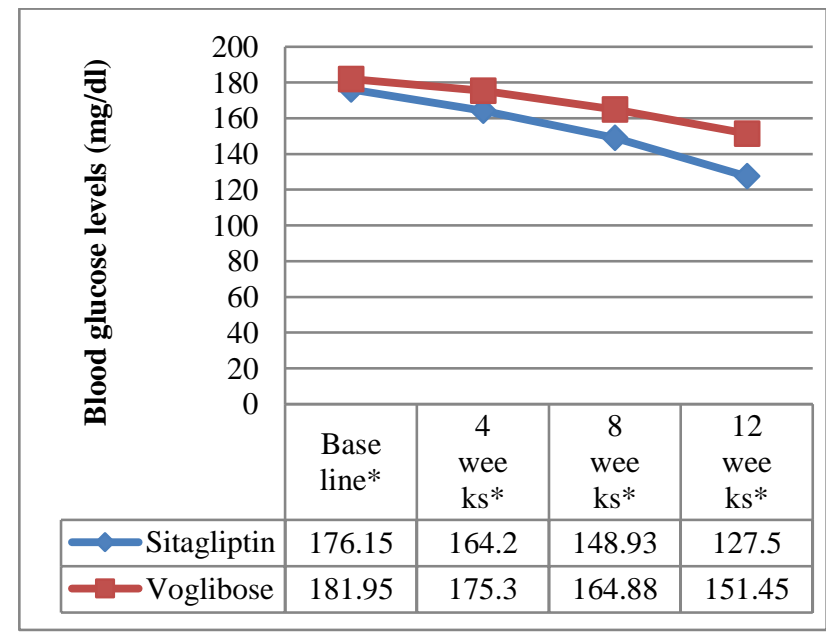

*Values expressed as Mean

Figure 1: Changes in FPG in both the study groups over the period of 12 weeks.

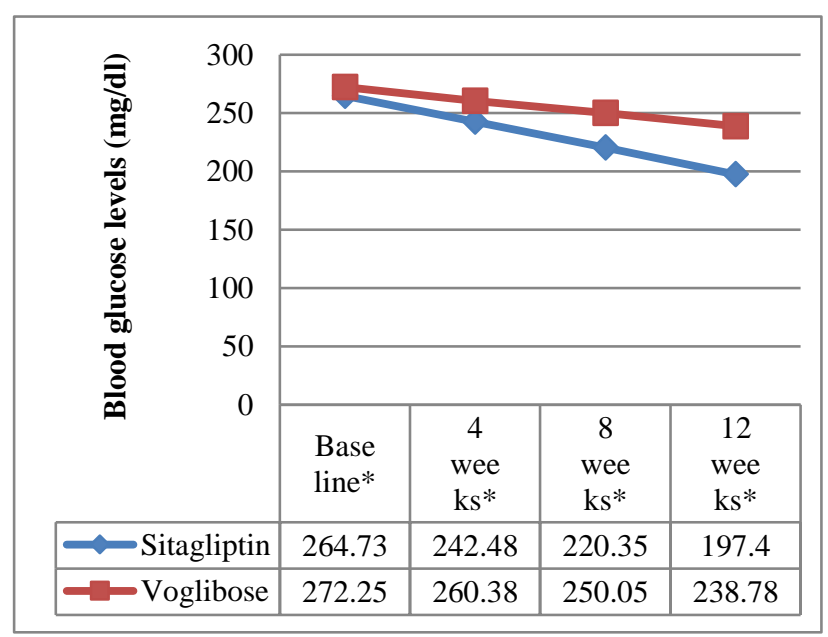

*Values expressed as Mean

Figure 2: Changes in PPG in both the study groups over the period of 12 weeks. 
Table 6: Adverse drug reactions in both the study groups during the study period of 12 weeks.

\begin{tabular}{|lll|}
\hline Adverse drug reactions & Group A & Group B \\
\hline Nausea & 3 & 1 \\
\hline Gastritis & 1 & 0 \\
\hline Nasopharyngitis & 2 & 0 \\
\hline Loose stools & 1 & 6 \\
\hline Headache & 1 & 0 \\
\hline Bloating & 0 & 6 \\
\hline Flatulence & 0 & 5 \\
\hline Total & 8 & 18 \\
\hline
\end{tabular}

At the end of 12 weeks, 24 patients in the sitagliptin group and 3 patients in the voglibose group achieved the target FPG of $<130 \mathrm{mg} / \mathrm{dl}$ and this was found to be significant $\left(\chi^{2}=24.654, p<0.05\right)$. In addition, 7 patients achieved the target PPG of $<180 \mathrm{mg} / \mathrm{dl}$ in the sitagliptin group whereas none achieved it in the voglibose group. Throughout the study period majority of the patients in sitagliptin group $(n=34)$ and voglibose group $(n=29)$ followed the dietary advice suggested by the dietician.

There was a total of 26 adverse drug reactions seen in the study. Group A had a total of 8 adverse drug reactions whereas Group B had a total of 18 adverse drug reactions (Table 6). None of the adverse drug reactions reported was serious in nature or required hospitalization and was treated with either reconciling or by giving symptomatic treatment. None of the patients discontinued the study due to adverse drug reactions. There was a significant difference between the total adverse drug reactions of the two groups $\left(\chi^{2}=5.698, \mathrm{p}<0.05\right)$.

\section{DISCUSSION}

Study by Matsushima $\mathrm{Y}$ et al, for demonstrating the pleiotropic effects of sitagliptin and voglibose as an add on therapy showed the BMI at baseline in the sitagliptin group to be $24.9 \pm 4.5 \mathrm{~kg} / \mathrm{m}^{2}$ and $25.1 \pm 4.5 \mathrm{~kg} / \mathrm{m}^{2}$ in the voglibose group, which was similar to our study in which the baseline BMI in group A and group B were $26.999 \pm 2.641 \mathrm{~kg} / \mathrm{m}^{2}$ and $26.075 \pm 2.979 \mathrm{~kg} / \mathrm{m}^{2}$ respectively. ${ }^{14}$ BMI values are defined according to the recommendations of Indian Council of Medical Research for Indians. A person is said to be obese if $\mathrm{BMI}$ is $\geq 25 \mathrm{~kg} / \mathrm{m}^{2}$, overweight if BMI is between $23-24.9 \mathrm{~kg} / \mathrm{m}^{2}{ }^{15}$

In the above study, the change in BMI at 12 weeks was not significant in the sitagliptin group $\left(24.9 \pm 4.4 \mathrm{~kg} / \mathrm{m}^{2}\right)$ but was significant in the voglibose group $\left(24.9 \pm 4.4 \mathrm{~kg} / \mathrm{m}^{2}\right)$. In contrast to this, there was a significant decrease in BMI in both sitagliptin $\left(26.798 \pm 2.592 \mathrm{~kg} / \mathrm{m}^{2}\right)$ and voglibose group $\left(25.931 \pm 2.937 \mathrm{~kg} / \mathrm{m}^{2}\right)$ in our study. The reason for significant reduction of BMI can be due to follow of proper dietary advice as given by the dietician to the patients in both the groups of our study. The intergroup comparison for BMI in our study showed a non significant reduction which is in accordance with the above study.
The baseline HbA1c values in the present study were $9.895 \pm 0.148 \%$ in group A and $9.855 \pm 0.141 \%$ in group B. Study by Hermansen $\mathrm{K}$ et al, comparing efficacy and safety of sitagliptin with placebo as add on therapy to metformin and glimepiride had a baseline HbA1c value of $8.27 \pm 0.73 \%$, which was much lower compared to that found in our study. ${ }^{16}$ Another study conducted by Rao C et al, for evaluation of efficacy and safety of voglibose as add on therapy to metformin and glimepiride had a baseline HbA1c value of $8.86 \pm 0.711 \%$, which was also much lower compared to our study. ${ }^{17}$ Both the groups in our study were comparable in terms of their baseline HbA1c values. Study by Yokoh $\mathrm{H}$ et al, which compared efficacy and safety of DPP-4 inhibitor and $\alpha$-glucosidase inhibitor showed that the patients in the sitagliptin group achieved $\mathrm{HbAlc}$ target value of $<7 \%$ at the end of 12 weeks which was in contrast to our study where none of the patients achieved the target $\mathrm{HbA} 1 \mathrm{c}$ value of $<7 \%$ or reduction by $1.5 \%$ by the end of 12 weeks. ${ }^{18}$ This could be due to higher baseline HbA1c values of the patients in our study and shorter duration of study.

At the end of 12 weeks the HbA1c decreased by $0.488 \pm 0.056 \%$ in the sitagliptin group. This reduction was found to be significant within the group. The mean reduction was not in accordance with the study by Hermansen $\mathrm{K}$ et al, showing a reduction in $\mathrm{HbA1c}$ by $0.59 \%$ with sitagliptin at 24 weeks. ${ }^{16}$ Yokoh $\mathrm{H}$ et al, also showed a reduction with sitagliptin by $0.7 \%$ at the end of 12 weeks which was not in contrast with our study. ${ }^{18}$ In our study the HbA1c value for the voglibose group reduced by $0.235 \pm 0.073 \%$ at the end of 12 weeks. This reduction was found to be significant within the group. Jha VK et al, demonstrated a decrease by $0.84 \%$ with voglibose as add on therapy to metformin and glimepiride. This difference was much higher as compared to our study. Reduction in HbA1c value of another study by Matsushima et al, showed a difference of $0.3 \%$ at the end of 12 weeks which was in accordance to our study. ${ }^{14}$ Shorter duration of study and higher baseline $\mathrm{HbAlc}$ values may be the reason for such deviations in reduction in both the groups. When comparing between group differences of HbA1c sitagliptin showed a higher reduction as compared to the voglibose group and this was found to be significant. Yokoh $\mathrm{H}$ et al, also demonstrated a higher and significant reduction with sitagliptin at 12 weeks. ${ }^{18}$

The mean baseline FPG was $176.15 \pm 11.641 \mathrm{mg} / \mathrm{dl}$ in the sitaglitpin group and $181.95 \pm 11.873 \mathrm{mg} / \mathrm{dl}$ in the voglibose group. The study conducted by Schernthaner $\mathrm{G}$ et al, comparing efficacy and safety of canagliflozin and sitagliptin as add on therapy to metformin and glimepiride had a baseline FPG value of $165.8 \pm 44.9 \mathrm{mg} / \mathrm{dl}$ in sitagliptin group which was lower than that of our study. ${ }^{19}$ Patients who were treated with voglibose in the study by Jha VK et al, had a baseline FPG value of $148 \pm 35 \mathrm{mg} / \mathrm{dl}$, which was much lower compared to our study. ${ }^{20}$ In our study, the change in FPG values at week 4, 8 and 12 in the sitagliptin group were $164.20 \pm 11.246 \mathrm{mg} / \mathrm{dl}, 148.93 \pm 11.025 \mathrm{mg} / \mathrm{dl}$ and $127.50 \pm 10.551 \mathrm{mg} / \mathrm{dl}$ respectively. These changes 
were found to be significant at $\mathrm{p}<0.05$. Similarly, in the voglibose group the change in FPG values at 4,8 and 12 weeks were $175.30 \pm 11.316 \mathrm{mg} / \mathrm{dl}, 164.88 \pm 11.303 \mathrm{mg} / \mathrm{dl}$ and $151.45 \pm 10.471 \mathrm{mg} / \mathrm{dl}$ respectively. These changes were also found to be significant at $p<0.05$. Secondary end point of FPG was reached by 24 patients in the sitagliptin group and only 3 patients in the voglibose group at the end of 12 weeks with the combination therapy.

The mean PPG in the sitagliptin group reduced from $264.73 \pm 15.768 \mathrm{mg} / \mathrm{dl}$ at baseline to $242.48 \pm 15.294 \mathrm{mg} / \mathrm{dl}$ to $220.35 \pm 15.177 \mathrm{mg} / \mathrm{dl}$ to $197.40 \pm 14.83 \mathrm{mg} / \mathrm{dl}$ at 4,8 and 12 weeks respectively. Likewise, the mean PPG in the voglibose group reduced from $272.25 \pm 15.060 \mathrm{mg} / \mathrm{dl}$ at baseline to $260.38 \pm 14.964 \mathrm{mg} / \mathrm{dl}$ to $260.38 \pm 14.964 \mathrm{mg} / \mathrm{dl}$ to $250.05 \pm 14.763 \mathrm{mg} / \mathrm{dl}$ to $238.78 \pm 14.892 \mathrm{mg} / \mathrm{dl}$. In both the groups this change was found to be significant at $p$ $<0.05$. Secondary end point of PPG was reached by 7 patients in the sitagliptin group and none in the voglibose group.

The FPG and PPG values at baseline were not comparable so to perform inter group analysis mean change was calculated which showed a higher and significant change in FPG at week $4(11.95 \pm 1.108 \mathrm{mg} / \mathrm{dl})$, week 8 $(27.23 \pm 1.493 \mathrm{mg} / \mathrm{dl})$ and week $12(48.65 \pm 2.045 \mathrm{mg} / \mathrm{dl})$ in the sitagliptin group. Similarly, mean change in PPG values also showed a higher and significant change at week $4(22.25 \pm 2.780 \mathrm{mg} / \mathrm{dl}), 8(44.38 \pm 2.072 \mathrm{mg} / \mathrm{dl})$ and 12 $(67.33 \pm 3.041 \mathrm{mg} / \mathrm{dl})$ in the sitagliptin group. Mean changes in both FPG and PPG were significant at $\mathrm{p}<0.05$. In the study by Liu SC et al, the mean change in the FPG of the sitagliptin group at 12 weeks was $22.8 \mathrm{mg} / \mathrm{dl}$ which was significant and but in contrast to the mean change from our study. ${ }^{21}$ Rao C et al, showed a decrement in FPG by $20.2 \mathrm{mg} / \mathrm{dl}$ at 12 weeks when voglibose was used as add on therapy to metformin and glimepiride. ${ }^{17}$ The mean change in PPG with voglibose in the same study at the end of 12 weeks was $64.4 \mathrm{mg} / \mathrm{dl}$. This was also in contrast to our study which showed a decrease in FPG at 12 weeks by $30.50 \pm 2.045 \mathrm{mg} / \mathrm{dl}$ which was significant within the group. Another study by Jha VK et al, showed a mean decrease in FPG with voglibose by $45 \mathrm{mg} / \mathrm{dl}$ at the end of 12 weeks which was higher than in our study. The mean reduction in PPG value from baseline at 12 weeks for the similar study was $76 \pm 16 \mathrm{mg} / \mathrm{dl}$ which was much higher as compared to our study. ${ }^{20}$ The reasons for the deviation from the reductions in blood glucose levels could be due to higher baseline values, absence of concomitant drugs in patients and shorter duration of our study.

There were 26 adverse drug reactions reported in our study. 8 adverse drug reactions were reported in total by the patients taking sitagliptin and 18 were reported by the patients taking voglibose. This difference in the total number of adverse drug reactions was found to be significant at $p<0.05$. This was in accordance with the study by Yokoh $\mathrm{H}$ et al. ${ }^{18}$ The most common adverse drug reaction observed with voglibose was of gastrointestinal in nature, which was also in accordance with the study. There were no episodes of hypoglycaemia reported in our study. Study by Nauck MA et al, reported a 32\% incidence of hypoglycaemia in patients being treated with sitagliptin and metformin. ${ }^{22}$ In the present open label randomized control study sitagliptin and voglibose as add-on therapy to metformin and glimepiride showed reduction in FPG, PPG and HbA1c. However, sitagliptin showed better glycemic control as compared to voglibose. So, it can be concluded that sitagliptin shows a better glycemic control as compared to voglibose as add on therapy to metformin and glimepiride. Major limitations of the study were small sample size, short follow up and lack of blinding in the study groups.

\section{ACKNOWLEDGEMENTS}

Authors would like to thank the management of Himalayan Institute of Medical Sciences for helping me in completion of the study. I would also like to thank the faculty of Department of Pharmacology, HIMS for smooth conduct of the study. A study is not complete without the cooperation of my fellow colleagues whose co-operation during the conduct of the study cannot be forgotten.

\section{Funding: No funding sources Conflict of interest: None declared}

Ethical approval: The study was approved by the Institutional Ethics Committee, Ethics Committee approval no.: SRHU/HIMS/ETHICS/2017/110

\section{REFERENCES}

1. Powers CA. Diabetes Mellitus. In: Kasper LD, Fauci SA, Hauser LS, Longo LD, Jameson LJ, Loscalzo J. Harrison's principles of internal medicine: 19th ed. United States of America: Mc Graw Hill Education; 2015:2399.

2. Ahirwar D, Tandia K, Agarawal S. Study of prevalence of diabetes mellitus in tertiary centre of Sagar. IOSR Journal of Dental and Medical Sciences. 2017;16:99-102.

3. Fonseca V. Clinical significance of targeting postprandial and fasting hyperglycemia in managing type 2 diabetes mellitus. Curr Med Res Opin. 2003;19:635-41.

4. Ceriello A. The glucose triad and its role in comprehensive glycaemic control: current status, future management. Int $\mathrm{J}$ Clin Pract. 2010;64(12):1705-11.

5. Setter SM, Iltz JL, Thams J, Campbell RK. Metformin hydrochloride in the treatment of type 2 diabetes mellitus: a clinical review with a focus on dual therapy. Clin Ther. 2003;25:2991-3026.

6. Cook MN, Girman CJ, Stein PP, Alexander CM, Holman RR. Glycemic control continues to deteriorate after sulfonylureas are added to metformin among patients with type 2 diabetes. Diabetes Care. 2005;28:995-1000. 
7. Inzucchi SE. Oral antihyperglycemic therapy for type 2 diabetes: scientific review. JAMA. 2002;287:36072.

8. Kalra S, Aamir AH, Raza A, Das AK, Khan AA, Shreshtha D, et al. Place of sulfonylureas in the management of type 2 diabetes mellitus in South Asia: A consensus statement. Ind $\mathrm{J}$ Endocrinol Meta. 2015;19(5):577-96.

9. Rodbard H, Jellinger P, Davidson J, Einhorn D, Garber A, Grunberger G, et al. Statement by an American Association of Clinical Endocrinologists/American College of Endocrinology consensus panel on type 2 diabetes mellitus: an algorithm for glycemic control. Endocrine practice. 2009; 15(6):540-59.

10. Karasik A, Aschner P, Katzeff H, Davies MJ, Stein PP. Sitagliptin, a DPP-4 inhibitor for the treatment of patients with type 2 diabetes: a review of recent clinical trials. Curr Med Res Opin. 2008;24:489-96.

11. Mohan V, Yang W, Son HY, Xu L, Noble L, Langdon $\mathrm{RB}$, et al. Efficacy and safety of sitagliptin in the treatment of patients with type 2 diabetes in China, India and Korea. Diab Res Clin Pract. 2009;83:106116.

12. Yang W, Lin L, Qi J. The preventive effect of acarbose and metformin on the IGT population from becoming diabetes mellitus: a 3-year multicentral prospective study. Chin J Endocrinol Metab. 2001;17:131-4.

13. Phung OJ, Sobieraj DM, Engel SS, Rajpathak SN. Early combination therapy for the treatment of type 2 diabetes mellitus: systematic review and metaanalysis. Diabetes Obes Metab. 2014;16:410-7.

14. Matsushima Y, Takeshita Y, Kita Y, Otoda T, Kato KI,Wakkuri HT, et al. Pleiotropic effects of sitagliptin versus voglibose in patients with type 2 diabetes inadequately controlled via diet and/or a single oral antihyperglycemic agent: a multicenter randomized trial. BMJ Open Diabetes Res Care. 2016;4:e000190.

15. Gupta R, Rehan H, Rohatgi A, Bhatacharjee J, Chopra D. The effect of glipizide, metformin and rosiglitazone on non traditional cardiovascular risk factors in newly diagnosed patients with type 2 diabetes mellitus. Inter J Diabetes developing countries. 2010;30(3):123-8.

16. Hermansen K, Kipnes M, Luo E, Fanurik D, Khatami H, Stein P. Efficacy and safety of the dipeptidyl peptidase-4 inhibitor, sitagliptin, in patients with type
2 diabetes mellitus inadequately controlled on glimepiride alone or on glimepiride and metformin. Diabetes, Obesity Metabolism. 2007;9:733-45.

17. Rao C, Faruqui. Efficacy and safety of oral triple drug combination (voglibose, glimepiride and metformin) in the management of type 2 diabetes mellitus. Int $\mathbf{J}$ Cur Res Rev. 2013;5(16):20-6.

18. Yokoh H, Kobayashi K, Sato Y, Takemoto M, Uchida D, Kanatsuka A, et al. Efficacy and safety of dipeptidyl peptidase-4 inhibitor sitagliptin compared with alpha-glucosidase inhibitor in Japanese patients with type 2 diabetes inadequately controlled on metformin or pioglitazone alone (Study for and ultimate combination theapy to control diabetes with sitagliptin-1): A multicenter, randomized, open label, non-inferiority trial. J Diabetes Invest. 2015;6(2):18291.

19. Schernthaner G, Gross JL, Rosenstock J, Guarisco M, $\mathrm{Fu}$ M, Yee J, et al. Canagliflozin compared with Sitagliptin for Patients with Type 2 Diabetes who do not have adequate glycemic control with Metformin plus Sulfonylurea: A 52-week randomized trial. Diabetes Care. 2013;36(9):2508-15.

20. Jha VK, Faruqui AA. Evaluation of safety and efficacy of triple drug fixed dose combination of voglibose, glimepiride and metformin in type 2 diabetes mellitus. Int J Clin Surg adv. 2014;2(4):26-33.

21. Liu SC, Chien KL, Wang $\mathrm{CH}$, Chen WC, Leung $\mathrm{CH}$. Efficacy and safety of adding pioglitazone or sitagliptin to patients with type 2 diabetes insufficiently controlled with metformin and sulfonylurea. Endocrine practice. 2013;19(6):980-8.

22. Nauck MA, Meininger G, Sheng D, Terranella L, Stein PP. Efficacy and safety of dipeptidyl peptidase4 inhibitor, stagliptin compared with sulfonylurea, glipizide in patients with type 2 diabetes inadequately controlled on metformin alone: a randomized, doubleblind, non inferiority trial. Diabetes, Obesity Metabolism. 2007;(9):194-205.

Cite this article as: Sahai $\mathrm{R}$, Sharma $\mathrm{T}$, Dhasmana DC, Kaeley N. Comparative efficacy and safety of DPP-4 inhibitors and $\alpha$-glucosidase inhibitors as add on therapy in type 2 diabetes. Int $\mathrm{J}$ Basic Clin Pharmacol 2018;7:707-13. 